Laboratory animals

\section{US protection act approved}

Washington

SHORTLY before its Christmas break, the US Congress passed legislation supported both by animal welfare campaigners and by researchers' organizations designed to improved standards of care for laboratory animals. The Improved Standards for Laboratory Animals Act requires painful experiments to be justified to a committee that includes at least one disinterested member of the public charged with ensuring that pain and distress are minimized.

The new act was introduced by Senator Robert Dole (Republican, Kansas) and Representative George Brown (Democrat, California) with 136 co-sponsors. Animal welfare workers, chiefly the Society for Protective Animal Legislation, worked for two years with researchers' organizations to find acceptable compromise provisions. The bill as passed was supported by, among others, the America Society for the Protection of Cruelty to Animals, the Humane Society of the United States, the American Physiological Society and the Association of Professors of Medicine.

The chief effect of the new act is to require the creation of Institutional Animal Committees that must include one external member; at present, many but not all institutions which carry out research on animals have such committees. The committees will be required to conduct semiannual inspections of research facilities and to report violations of regulations to institutional and federal authorities. The Secretary of Agriculture is empowered to promulgate regulations on care, treatment and practices to minimize pain and distress, but not on the conduct of experiments.

The new act also requires institutions to provide training in the humane treatment of animals, encourages alternatives to animal testing where possible and requires principal investigators to certify that alternatives have been considered. Exercise for laboratory dogs, use of anaesthesia with paralysants and limitations on repeated major operations on the same animal are also specified.

A new information service at the National Agricultural Library is established under the act, in order to minimize unintended duplication of experiments, and both federal and private laboratories are subject to its provisions. Although the act makes clear that experimental protocols will be respected, it is required to suspend federal support if an agency determines that animal care in a particular project has been persistently unacceptable.

Tim Beardsley

Bhopal disaster

\title{
India blames Union Carbide
}

New Dehli

INDIA's official report on the events leading to the Bhopal disaster last year says that about half a tonne of water had entered the tank containing methyl isocyanate (MIC), thus confirming the findings of Union Carbide. But the report says that the chemical reaction leading to a catastrophic increase of temperature was caused by contamination of the tank by metal ions, which acted catalytically.

The report is the work of a 16-member committee led by Dr S. Varadarajan, the chemist who is now the secretary-general of the Department of Scientific and Industrial Research. It specifically disputes Union Carbide's claim that entry of large quantities of water alone was responsible for the ghastly accident on 2 December 1984, saying that the runaway reaction leading to a rapid rise of temperature and pressure in the storage tank could have been triggered by water only if the MIC inside the tank had also been contaminated with metallic impurities.

The report, by implication, rules out sabotage, alleged by Union Carbide, and instead puts the blame on the US company for its choice of unsuitable corrodable materials for the piping thought to have been the source of the contamination.

Varadarajan's committee reached its conclusions on the basis of experiments carried out on a second undamaged storage tank at Bhopal. The experiments included heating MIC alone and reacting it in the presence of water, chloroform and traces of ferric salts and sealed containers at temperatures up to 250 degrees centigrade. These simultations yielded all the twelve or so different types of solid residues found inside the damaged tank.

Based on these experimental data and an actual inventory of the tank residues, it was estimated that $12,087 \mathrm{~kg}$ of MIC and $595 \mathrm{~kg}$ of chloroform (used as a solvent) reacted with $512 \mathrm{~kg}$ of water, producing enough heat to vapourize the remaining 28 tonnes of MIC in the tank. The report says that the escaped gas also included 80 $\mathrm{kg}$ of ammonia and 1.25 tonnes of carbon dioxide.

The Varadarajan report has incidentally put to rest the controversy over whether the gas that leaked was MIC, cyanide or both. Union Carbide had from the beginning insisted that cyanide was not present, but Indian doctors who carried out autopsies on gas victims suspected otherwise. The report agrees with Union Carbide on the basis of the experimental evidence it has collected.

The most important finding of the Varadarajan committee relates to the role of water. Union Carbide maintains that the runaway reaction was due to the addition of large amounts of water to MIC containing chloroform. The Indian report says that ingress of $500 \mathrm{~kg}$ of water would at best have consumed four tonnes of $\mathrm{MIC}$ and raised the tank temperature to just 70 degrees centigrade, below the boiling point of MIC (at the safety valve pressure). The report also says that chloroform could not have catalysed the reaction below 200 degrees centigrade, whence the conclusion that some other catalyst must have been involved.

From the products of tank residues, calculated heats of chemical reactions and the extent of bulging in the tank, the committee estimated that the tank reached a temperature above 250 degrees centigrade. According to the report, only "the onset of metal-ion catalysed polymerization of MIC" could account for this rapid increase of temperature.

The Varadarajan committee says that the metallic contaminants (iron and sodium) came from corroded pipes and the tank itself and catalysed the trimerization of MIC. Subsequent entry of water hydrolysed the MIC, producing heat and carbon dioxide and allowing "trimerization to take off with explosive violence".

In support of this theory, the report lists iron, sodium, chromium and nickel among the metallic contaminants found inside the exhumed tank. Sodium was present at a level of 60 p.p.m., equivalent to 25 litres of 5 per cent sodium hydroxide. According to the report, the contaminants most probably came from tank accessories made of materials such as carbon steel and copper.

The source of sodium is identified as the vent gas scrubber. One source of iron was found to be the tank itself, probably released as ferric iron as a result of corrosion caused by hydrochloric acid formed by the hydrolysis of phosgene.

Exactly how the contaminants and half a tonne of water came to enter the tank, the report can only guess. Indirectly, the report rules out sabotage by the argument that while it may be easy to pour water into the tank, a saboteur would not know the role of metallic contaminants.

The report concludes that the gas leak would have been avoided had the 42 tonnes of MIC been stored in several small steel drums. "The needless storage of large quantities of MIC for long periods, as well as insufficient caution in design, choice of materials for construction and provision of measuring and alarm instruments, together with inadequate controls on systems of storage and quality of stored materials as well as lack of necessary facilities for quick and effective disposal material exhibiting instability led to the accident." K.S.Jayaraman 